\title{
O ENSINO DE ARTE E O DESENVOLVIMENTO DO POTENCIAL CRIATIVO DA CRIANÇA NA ESCOLA DO ENSINO FUNDAMENTAL
}

Art teaching and the development of the child's potential creative in the school of fundamental education

La enseñanza del arte y el desarrollo de la potencial creativa del niño en la escuela de educación fundamental

\section{Floriene Pereira de Souza ${ }^{1}$, Edna Maria Cruz Pinho², Maria José da Silva Morais ${ }^{3}$}

${ }^{1}$ Especialista em Arte e Educação pelo Instituto Federal do Tocantins ( IFTO), Graduação em Pedagogia pela Universidade Estadual do Tocantins, Gurupi, Brasil.

${ }^{2}$ Graduação em Pedagogia (UEPA-PA), Pós Graduação Lato Sensu em Orientação Educacional (UNIVERSO / 1997) e mestrado em Educação (UFT/TO). Formação em Coach (IAPERFOMA/SP), Gurupi, Brasil.

${ }^{3}$ Mestre em Educação pela Universidade Federal do Tocantins ( UFT/TO). Pós Graduação em Docência do Ensino Superior pela Faculdade de Ciências Aplicadas de Marabá- PA. Graduada em Pedagogia pela Universidade Federal do Tocantins ( UFT-TO), Palmas, Brasil.

*Correspondência: Laboratório de Ciências, Instituto de Ensino Superior, Av. NS 15, 109 Norte, Palmas,

Tocantins, Brasil. CEP:77.010-090.e-mail florienesouza@hotmail.com.

Artigo recebido em 12/03/2020 aprovado em 06/11/2020 publicado em 01/12/2020.

\section{RESUMO}

O artigo discute sobre arte e o potencial criativo da criança, e tem como objetivo refletir sobre a importância da arte para o ensino e para a formação e atuação criativa da criança. $\mathrm{O}$ estudo de abordagem qualitativa e tem na pesquisa bibliográfica a base de sua organização e sistematização. A reflexão que se faz é que o ensino de arte permite que o aluno desenvolva aspectos como a percepção, sensibilidade, a espontaneidade, a expressividade, a consciência de si, dos outros indivíduos e das diversas culturas que o envolve em seu meio social. Conclui-se que é importante que a escola inclua práticas criativas nas atividades do dia a dia, que o processo educativo se torne significativo, sendo o professor o incentivador da expressão criativa do aluno, assim como, da valorização não apenas dentro da sala de aula, mas as diversas linguagens artísticas que podem e devem ser trabalhadas em sala de aula: música teatro, dança e artes visuais respeitando os direitos de aprendizagem como: brincar, conviver, participar, expressar, explorar e conhecer a si mesmo. Portanto, a educação através da arte tem um importante desenvolvimento da criatividade, e o professor é o principal incentivador da expressão criativa do aluno.

Palavras-chave: Criatividade, arte, escola

\section{ABSTRACT}

He article discusses art and the creative potential of the child and aims to reflect on the importance of art for teaching and for the creative training and performance of the child. The study of qualitative approach and has in the bibliographic research the basis of its organization and systematization. The reflection that is made is that the teaching of art allows the student to develop aspects such as perception, sensitivity, spontaneity, expressiveness, selfawareness, the other individuals and the different cultures that involve him in his social environment. It is concluded that it is important that the school includes creative practices in day-to-day activities, that the educational process becomes meaningful, the teacher being the incentive of the creative expression of the student, as well as of appreciation not only within the classroom, but the different artistic languages that can and should be worked in the classroom: music theater, dance and visual arts. Learning rights are: play, socialize, participate, express, explore and know yourself. Therefore, education through art has an important development of creativity, being the teacher the incentive of creative expression of the student.

Keywords: Creativity, art, school. 


\section{RESUMEN}

El artículo analiza el arte y el potencial creativo del niño, y tiene como objetivo reflexionar sobre la importancia del arte para la enseñanza y para la formación y el desempeño creativo del niño. El estudio tiene un enfoque cualitativo y la investigación bibliográfica tiene la base de su organización y sistematización. La reflexión que se hace es que la enseñanza del arte permite al estudiante desarrollar aspectos como la percepción, la sensibilidad, la espontaneidad, la expresividad, la autoconciencia, de otros individuos y de las diferentes culturas que lo involucran en su entorno social. Concluimos que es importante que la escuela incluya prácticas creativas en las actividades diarias, que el proceso educativo se vuelva significativo, con el maestro alentando la expresión creativa del alumno, así como valorando no solo dentro del aula, pero los diversos lenguajes artísticos que se pueden y se deben trabajar en el aula: música, teatro, danza y artes visuales respetando los derechos de aprendizaje, tales como: tocar, socializar, participar, expresar, explorar y conocerse a sí mismo. Por lo tanto, la educación a través del arte tiene un desarrollo importante de la creatividad, y el maestro es el principal impulsor de la expresión creativa del alumno.

Descriptores: Creatividad, arte, escuela.

\section{INTRODUÇÃO}

De um ambiente escolar espera-se que favoreça o desenvolvimento do potencial criativo dos alunos e professores, que considere $\mathrm{o}$ ato de aprendizagem como base para um processo de mudança da forma de ver o mundo. As escolas, enquanto instituições formativas, tem papel importante no processo do desenvolvimento da criatividade das pessoas. De acordo com Oliveira e Alencar, (2012) a criatividade desperta da atenção dos alunos e os ambientes estimuladores, quando utilizam a arte despertam a sensibilidade estética.

Neste sentido, o objetivo deste artigo é refletir sobre a importância da arte para o ensino e para a formação humana, principalmente na educação da criança. Para isto, discute o conceito de criatividade e de potencial criativo e sua articulação com o ensino da arte na escola de ensino fundamental, e do uso de metodologias que incentivem a prática de projetos de arte na sala de aula estimulando a criatividade.

\section{MATERIAIS E MÉTODOS}

A proposta metodológica para este trabalho é a da pesquisa bibliográfica considerando que este tipo de investigação tem como finalidade de levantar um conhecimento disponível sobre teorias, a fim de analisar, produzir ou explicar um objeto a ser investigado. Segundo Severino (2007), a pesquisa bibliográfica é a que realiza o levantamento de bibliografias que já foram publicadas em fontes secundárias como livros, revistas, entre outras, e que utiliza esses dados para auxiliar na análise do conteúdo pesquisado.

$\mathrm{Na}$ pesquisa realizada foram consultadas literaturas relativas ao assunto em estudo, tais como livros, dissertações e artigos publicados sobre o assunto nos últimos 05 anos, principalmente na base de dados da Rede Internacional de Escolas Criativas Riec no Tocantins.

\section{O ENSINO DE ARTE}

A arte ocupa uma função indispensável na vida individual e social do ser humano. É por meio da arte que a criança desenvolve capacidade de expressão, de novas ideias, de se comunicar tanto pela linguagem verbal como não verbal e também de autoconhecimento. Para Barbosa (1975 p. 02 apud Garcia e Lopes), diz: “A arte não tem importância para o homem somente como instrumento para desenvolver sua criatividade, sua percepção, etc.; mas tem importância em si mesma, como assunto, como objeto de estudos".

Pensando neste aspecto, é importante que o educador desenvolva práticas de ensino que liberte e 
estimule o aluno a imaginar, a ter o senso crítico e senso estético, sempre respeitando o potencial criativo da criança e oportunizando o aperfeiçoamento da sua capacidade de produzir e executar atividades.

A escola é o elo entre o desejo do aluno em desenvolver atividades criativas e o que a sociedade propaga. É a dimensão social das manifestações artísticas as quais constitui funções importantes do ensino da arte nas suas diferentes linguagens, como previstos nos Parâmetros Curriculares e atualmente na Base Nacional Comum Curricular - BNCC.

Sobre as linguagens artísticas, a BNCC referindo-se as artes visuais e a dança, afirma

As Artes visuais são os processos e produtos artísticos e culturais, nos diversos tempos históricos e contextos sociais, que têm a expressão visual como elemento de comunicação. Essas manifestações resultam de explorações plurais e transformações de materiais, de recursos tecnológicos e de apropriações da cultura cotidiana [...]. A Dança se constitui como prática artística pelo pensamento e sentimento do corpo, mediante a articulação dos processos cognitivos e das experiências sensíveis implicados no movimento dançado. Os processos de investigação e produção artística da dança centram--se naquilo que ocorre pelo corpo, discutindo e significando relações entre corporeidade e produção estética [...].(BRASIL, 2017, p.197-198)

E sobre a música e o teatro, o documento diz:

A Música é a expressão artística que se materializa por meio dos sons, que ganham forma, sentido e significado no âmbito tanto da sensibilidade subjetiva quanto das interações sociais como resultados de saberes e valores diversos estabelecidos no domínio de cada cultura [...]. O Teatro instaura a experiência artística multissensorial de encontro com o outro em performance. Nessa experiência, o corpo é lócus de criação ficcional de tempos, espaços e sujeitos distintos de si próprios, por meio do verbal, não verbal e da ação física. Os processos de criação teatral passam por situações de criação coletiva e colaborativa, por intermédio de jogos, improvisações, atuações e encenações, caracterizados pela interação entre atuantes e espectadores. (BRASIL, 2017, p.197-198)

Neste sentido, a importância de conhecer e aprendizado que a criança adquire sobre costumes e outras formas de ver, perceber, produzir e criar. E dessa forma, aprende a compreender o outro, a lidar com as diferenças, assim como, desenvolve a consciência de preservar os patrimônios históricos, culturais e a respeitar a diversidade.

\section{A Arte na Legislação Brasileira}

A educação das crianças deve acontecer em um contexto que propicie o acesso a elementos culturais que contribuam para interação destas na sociedade (BRASIL, 1998). Um processo educacional que seja embasado na interação social pode contribuir para a construção da identidade das crianças, e fortalecer o desenvolvimento emocional, efetivo e cognitivo.

A Lei de Diretrizes e Bases da Educação Nacional $\mathrm{n}^{\circ}$ 9394, de 20 de dezembro de 1996, estabelece a obrigatoriedade da arte na educação básica nas suas diferentes etapas: educação infantil, ensino fundamental e ensino médio. $\mathrm{O}$ texto dos Parâmetros Curriculares Nacionais (1997) ressalta a importância do ensino de Arte e seu caráter interdisciplinar no ambiente escolar

Esta área também favorece ao aluno relacionarse criadoramente com as outras disciplinas do currículo. Por exemplo, o aluno que conhece arte pode estabelecer relações mais amplas quando estuda um determinado período histórico. Um aluno que exercita continuamente sua imaginação estará mais habilitado a construir um texto, a desenvolver estratégias pessoais para resolver um problema matemático. (BRASIL, 1997, p. 19).

A arte na escola transforma, desenvolve, cria e tem a capacidade de resolver problemas é o momento em que o aluno, com autonomia, começa a contemplar o trabalho artístico, interpretando e identificando suas características. Neste aspecto, a BNCC ao reafirmar a importância da arte para o ensino, acentua seus valores e consolida a obrigatoriedade da área. 
Base Nacional Comum Curricular - BNCC

A Base Nacional Comum Curricular- BNCC referenda o aprendizado essencial que o aluno da Educação Básica deve desenvolver durante sua trajetória escolar. Segundo o MEC “[...] a BNCC soma-se aos propósitos que direcionam a educação brasileira para a formação humana integral e para a construção de uma sociedade justa, democrática e inclusiva". (BRASIL, 2017, p. 7)

Almeida (2001) diz que a BNCC traz uma concepção que dá ênfase a Arte como área de conhecimento numa visão essencialista, e enfatiza que

[...] os alunos devem expandir seu repertório e ampliar sua autonomia nas práticas artísticas, por meio da reflexão sensível, imaginativa e criativa sobre os conteúdos artísticos e seus elementos constitutivos e também sobre as experiências de pesquisa, intervenção e criação. [...] A progressão das aprendizagens não está proposta de forma linear, rígida ou cumulativa com relação a cada linguagem ou objeto de conhecimento, mas propõe um movimento no qual cada nova experiência se relaciona com as anteriores e as posteriores na aprendizagem de Arte (BRASIL, BNCC, 2017, p.195)

Estimular o desenvolvimento do potencial criativo do aluno do Ensino Fundamental, por meio do ensino de arte é importante no que diz a respeito à vivência artísticas como prática social. Elas possibilitam que os alunos sejam os autores e principais e criadores de suas ideias.

Neste sentido, várias práticas podem ser realizadas tais como: por meio de exposições, saraus, espetáculos, performances, concertos, recitais, intervenções e outras apresentações e eventos artísticos e culturais, na escola ou em outros locais. A criação artística faz com que o aluno perceba a sua poética pessoal (BRASIL, 2017), se torne sensível ao mundo ao redor e aprenda a refletir de forma ampla e com atitudes autônomas no percurso do processo criativo.
Para os Parâmetros Curriculares Nacionais -

PCNs em Arte para os anos iniciais do Ensino Fundamental, a educação nesta área propicia o aumento da imaginação, da sensibilidade, da reflexão e da percepção. Para este documento ao conhecer a arte, o educando pode envolver-se de forma mais criativa com as outras disciplinas.

Os PCNs apresentam a arte como um conjunto de manifestações simbólicas e objeto de conhecimento de uma cultura, fazendo assim uma ligação entre a arte e a ciência, ao expor que "para um cientista uma fórmula pode 'ser bela', para um artista plástico, as relações entre a luz e as formas são problemas a serem resolvidos plasticamente" (BRASIL,1997, p.27)".

A sugestão é que o estudo curricular da arte seja dividido em cinco linguagens: artes visuais, dança, teatro, música e dança. Propõe ainda, que as atividades desenvolvidas possibilitem que os alunos tenham percepção, ao realizar uma peça teatral, da relação de uma linguagem artística com outra, neste caso, da linguagem teatral com a música, por exemplo. Sugere ainda, que professor seja o responsável em promover variações nas linguagens artísticas trabalhadas.

Para que se desenvolva um bom trabalho de Arte é necessário que o professor descubra quais os interesses dos alunos, vivências que possuem sobre o conhecimento e a prática em arte. Estes saberes são imprescindíveis ao educador, pois serão como base para o ensino de arte criativo e dinâmico.

A arte agrupa um acervo de conhecimentos que envolvem expressão, criação, comunicação e interação social, fatores que são indispensáveis para o processo de formação da criança.

A arte se constitui num estímulo permanente para que nossa imaginação flutue e crie mundos possíveis, novas possibilidades de ser e sentir-se. Pela arte a imaginação é convidada a atuar, rompendo o estreito espaço que o cotidiano lhe reservava. (DUARTE JR, 1985, p.67) 
Neste aspecto, justifica-se a inclusão da arte no currículo escolar pela a capacidade de conscientizar os educandos de suas habilidades criativas. Sendo que a mesma contribui para o desenvolvimento da personalidade e do senso crítico de si e da sociedade. Bessa (1972, p. 13) a este respeito comenta,

\begin{abstract}
Quando a criança pinta, desenha, modela ou constrói regularmente, a evolução se acelera. Ela pode atingir um grau de maturidade de expressão que ultrapassa a medida comum. Por outro lado, a criação artística traz a marca de uma individualidade, provoca libertação de tensões e energias, instaura uma disciplina formativa, interna de pensamento e de ação que favorece a manutenção do equilíbrio tão necessário para que a aprendizagem se processe sem entraves, e a integração social sem dificuldades.
\end{abstract}

A liberdade de se expressar é o meio pelo qual a criança revela a sua essência da personalidade, pois subentende a representação e exteriorização. "Um aluno que exercita continuamente sua imaginação estará mais habilitado a construir um texto, a desenvolver estratégias pessoais para resolver um problema matemático.” (BRASIL,1997, p.19)

Tanto a ciência quanto a arte, respondem a essa necessidade mediante a construção de objetos de conhecimento que, juntamente com as relações sociais, políticas e econômicas, sistemas filosóficos e éticos, formam o conjunto de manifestações simbólicas de uma determinada cultura. Ciência e arte são, assim, produtos que expressam as representações imaginárias das distintas culturas, que se renovam através dos tempos, construindo o percurso da história humana (BRASIL, 1997, p.26).

Os PCNs de arte deixam claro sobre os conteúdos que auxiliam na formação da disciplina em artes, e as linguagens como teatro, dança e música que auxiliam na produção artística do aluno. No entanto, é notório que nem sempre o que está na teoria acontece na prática, e isso não é diferente no ensino da arte em escolas, isso se dá, entre outras questões, por falta do acesso dos educadores materiais que os auxiliam no ensino da arte e ausência de formação continuada que os oriente a planejar aulas mais dinâmicas e criativas.

$\mathrm{O}$ texto do documento aponta para a problemática quando diz que: “em muitas escolas ainda se utiliza, por exemplo, o desenho mimeografado com formas estereotipadas para as crianças colorirem, ou se apresentam 'musiquinhas' indicando ações para a rotina escolar (hora do lanche, hora da saída)" (BRASIL, 1997, p. 26).

Há escolas que não tem o suporte necessário para a realização do ensino da arte, não possuem materiais didáticos para que a disciplina seja ministrada de forma criativa e que chame a atenção do aluno. Há situações em que não há professores de arte formados, principalmente nas escolas das cidades nos interiores. Assim como, há professores que possuem os recursos necessários, mas que não usam a sua imaginação para criar planos de aula aonde possam dá aulas de forma criativa e que desperte o imaginário da criança, conforme seu desenvolvimento.

O processo do desenvolvimento da criança envolve mudanças de características físicas, cognitivas e psicossociais e que se modificam com o tempo. Essas características tanto são influenciadas pela hereditariedade, como pelo ambiente em que a criança está inserida, como as experiências que lhe são proporcionadas, estimuladas e oportunizadas.

Há diversas abordagens que tentam explicar o comportamento inteligente da criança, uma delas, feita por Souza e Wechsler (2014), entre outras tantas, mostra como a mente estrutura as atividades que irão ser realizadas, de como se adapta no ambiente em que está sendo inserida, em que e quando a criança é atuante na construção do seu conhecimento, principalmente quando está explorando ao seu redor, particularmente na área de artes e nas experimentações e criações que a área estimula.

Neste entendimento, a escola pode proporcionar ao indivíduo oportunidade de enfrentar 
desafios e dominar as habilidades novas que irão surgindo no decorrer do seu desenvolvimento. A satisfação que a criança experimenta com as conquistas auxilia na construção de julgamentos positivos em relação as suas habilidades cognitivas, motoras e sociais, fazendo com que ganhe confiança sobre as suas ações e construindo autonomia para aprender e se tornar uma pessoa criativa e independente.

\section{Criatividade e Potencial criativo}

Não há uma definição em que haja adesão sobre o conceito de criatividade. Os estudos sobre esta questão abrangem diversos aspectos teóricos na pretensão de demonstrar a sua origem, subsistência e desempenho. Há autores que afirmam que a criatividade é uma parte complementar do funcionamento intelectual, sendo assim defendem a sua implementação como uma prática educativa em contexto escolar.

Há teóricos que confirmam que a criatividade está presente em todas as pessoas, no entanto, em diferentes medidas, e que podem ser desenvolvidas em níveis distintos. Para os mesmos, no momento da criação está presente a capacidade, formas de percepção, conhecimento e habilidades cognitivas, que juntos, tornam-se valores, motivação e emoção.

Para Lins e Miyata (2009, p.460), a criatividade possui quatro aspectos gerais que estão relacionados à cognição, conexão, domínio e dotação, como esclarecem

O primeiro aspecto é a necessidade de que conhecimentos e experiências prévias estejam disponíveis na estrutura cognitiva da pessoa criativa. O segundo aspecto é a relação entre a criatividade e a capacidade de buscar conexões e soluções distantes do óbvio ou do já conhecido. $\mathrm{O}$ terceiro aspecto é entender a criatividade como algo que se manifesta de acordo com o domínio daquela pessoa criativa. Se uma determinada pessoa tem domínio para se expressar por meio de poesia, a tendência é que esta pessoa consiga exercer seu pensamento criativo neste domínio específico. O quarto aspecto é a desmitificação da criatividade, desvinculando-se da [ideia] de que o pensamento criativo está presente em poucas pessoas dotadas de alto poder intelectual.

É evidenciado por Torrance (1974) que as variações nos níveis de criatividades dizem respeito a diferentes condições as quais os indivíduos estão submetidos. Estas condições podem ser elas externas e internas e envolvem a personalidade e a motivação do ser. Sendo assim, podem ser mais ou menos propícias as manifestações e refinamentos das habilidades criativas. A criatividade é um conjunto de capacidades as quais permitem que o indivíduo tenha um comportamento novo e adaptativo em diversos contextos, assim como a capacidade criar soluções inovadoras e apropriadas. Nesta dimensão, a criatividade interliga três fatores:

Capacidade e conhecimento ou habilidade de Domínio: consiste nas capacidades relativas a um domínio que inclui o talento, o conhecimento adquirido através do trabalho, da educação formal e informal, das experiências e as aptidões técnicas. Motivação Intrínseca: consiste no interesse particular que o indivíduo tem na realização da atividade, independentemente dos incentivos externos. Processo Criativo ou Competências Criativas: consiste no estilo de trabalho do criativo, o processo cognitivo, o domínio de estratégias propulsoras de novas ideias e do traço de personalidade do sujeito criativo (FARIAS, 2010 p. 51).

A interligação destes fatores mencionados busca as influencias sociais, motivacionais e de personalidade para que expresse o potencial criativo em busca da educação, habilidade, conhecimento, aspectos que estão ligados as diferentes técnicas de expressão que pressupõem a criação de algo novo.

\section{Criatividade na Escola}

O ambiente escolar como espaço de favorecimento da criatividade pode levar os alunos a criarem situações que os levem além do que lhes é oferecido, desenvolvendo cada vez mais 
comportamentos que motivam ações criativas em sala de aula, gerando um ensino que promova o pensamento flexível, evitando julgamentos e críticas às ideias dos colegas e estimulando a autoavaliação (ASSIS, 2009).

Para Oliveira e Alencar (2012, p.550), “O contexto escolar constitui, sem sombra de dúvidas, um dos locais mais férteis ao desenvolvimento da criatividade". Sobre este assunto, o grupo de Pesquisa em Rede Investigando Escolas Criativas e Inovadoras do Tocantins membro da rede Internacional de escolas Criativas - RIEC a partir das pesquisas mestrado desenvolvidas por seus membros conta a experiência da Escola de Tempo Integral Daniel Batista em Palmas -TO, que por meio dos projetos "Declamadores de Poesias e Estudar é o meu Maior Tesouro" demonstrou que possui indícios de criatividade no desenvolvimento de sua prática pedagógica, e mesmo diante das adversidades, estimula a criatividade dos alunos e contribui para o crescimento de cada criança (PINHO, et al., 2015).

Outro exemplo a ser mencionado diz respeito a Escola Orlindo Pereira da Mota em Gurupi - TO, que possui a experiência pedagógica do projeto "Educando pela diferença para a diversidade cultural afrobrasileira: Dois Povos Unidos por uma Cultura" que trata a respeito da desigualdade racial. Neste projeto os gestores, professores e alunos puderam manifestar vínculos emocionais e afetivos, e estimularam manifestações criativas, espírito de liberdade e igualdade na comunidade (PINHO, et al., 2015). A escola também apresenta resultados significativos nos indicadores de criatividade analisados segundo o Instrumento de Identificação do Desenvolvimento Criativo de Instituições de Ensino (VADECRIE).

Em ambas as experiências citadas, é notória atuação do professor na utilização de metodologias diversificadas que proporcione espaços que sejam favoráveis para que a criança crie, utilize de recursos criativos que seja próprio. Pode se dizer que a criatividade do educador se torna um fator de suma importância, ou seja, essencial dentro da sala de aula e principalmente ao realizar o planejamento das aulas. $\mathrm{O}$ professor tem um papel fundamental no desenvolvimento do potencial criativo da criança, pois é ele quem define estratégias e objetivos para que a criatividade da criança seja estimulada e seja capaz de criar de maneira inovadora.

Ao estimular a criatividade em sala de aula, permite que a criança pense, desenvolva ideias, e dê seu ponto de vista. E assim, cria oportunidades para que os alunos tenham consciência do seu potencial criativo, e demonstre entusiasmo pela atividade que está executando. Para Nascimento (2013, p. 90) “a criatividade é exercício da liberdade de pensar, de agir, de ser, além dos padrões que adotamos. Ser criativo implica uma atitude livre, a partir da qual se assume um papel de responsabilidade pela criação (criar + ação) de sua própria realidade".

A criança tem a capacidade criar desde que ela seja capaz de pensar. Uma atividade criadora se constitui uma necessidade biológica cuja satisfação é absolutamente necessária para desenvolver o ser humano em seu crescimento. É na infância que se encontra maior predisposição para se engajar no desconhecido.

Nesta fase da vida, encontram-se sedentas de descobrir o mundo a sua volta, e a atividades criativas provocam o prazer em fazer, despertam a curiosidade pelo desconhecido. E os educadores tem a possibilidade de incentivar as crianças para que realizem experiências novas e desafiadoras. (MOSER, 2015).

A escola possui um papel essencial na formação de alunos criativos, empreendedores e resilientes. As escolas quando são criativas tem por finalidade (Torre, 2009) de contribuir para uma educação atenta às necessidades presentes do século 
XXI, estimulando o desenvolvimento da consciência, de valores e da criatividade. Esta perspectiva é vista em experiências escolares como acontece na escola Pirineus.

\section{A escola Pirineus}

A escola Pireneus é uma instituição privada de Ensino Fundamental, criada em 2010 na cidade de Pirenópolis, uma importante cidade histórica do Estado de Goiás. Inicialmente a escola atendia crianças de 1 a 5 anos de idade, em 2012 iniciou sua primeira turma do Ensino Fundamental.

A visita Escola Pirineus teve a finalidade de realizar uma vivência orientada pela professora Edna Maria Cruz Pinho na disciplina de Ateliê de Artes Visuais no Curso de Pós-Graduação em Arte Educação da Instituto Federal de Educação, Ciência e Tecnologia do Tocantins -IFTO Campus Gurupi.

Em 2016 foi iniciada uma parceria com a editora da Vila adotando um material didático sob a perspectiva da pedagogia ecossistêmica. Neste material os conteúdos são trabalhados de forma contextualizada e transdisciplinar por meio de projetos e atendem rigorosamente o que é determinado pelo currículo Estadual e Municipal de ensino, em suas respectivas sedes. Ao todo são desenvolvidos 6 projetos subdivididos, em aulas que interligam as disciplinas a partir de um mesmo tema. A pedagogia de projetos possibilita estudantes vivenciarem aplicabilidade dos conteúdos programáticos e a consequente reconstrução e ressignificação de conceitos (LIMAVERDE et al. 2014).

Mesmo antes de adotar a pedagogia ecossistêmica, a Escola Pireneus já havia adotado como missão princípios da sustentabilidade e o envolvimento com a consciência planetária. A maior parte das edificações da escola são: biconstruídas, ou seja, valem -se de materiais que não agridem o meio ambiente e minimizam o impacto ambiental, com o reaproveitamento de recursos. As salas de aula são construídas com materiais naturais e sustentáveis, são empregadas técnicas como: superadobe, $\mathrm{COB}$, ferrocimentos entre tantas outras que promovem um ambiente seguro, aconchegante e muito bonito.

As crianças participam de todo este processo, reciclam materiais como plástico e papeis e o material orgânico e devolvido para a terra, por meio de composteiras. Acredita-se que uma das justificativas da parceria entre a Escola Pirineus e a Escola Vila, seja a preocupação com o futuro do planeta e o comprometimento do ensino voltado com as questões ambientais sem se afastar dos conteúdos curriculares vigentes.

A partir da metodologia adotada, a escola procura levar os alunos a entender e valorizar as diferentes linguagens artísticas como a música, teatro, dança e artes visuais. Estimula a realização de atividades que transitam e integram as linguagens artísticas, facilmente identificadas na rotina da escola, tais como o cultivo das hortas e pomares, a reciclagem de materiais para bioconstrução e a interação que esta prática promove com a arte presente nas estruturas arquitetônicas, assim como, a experiência da contemplação, da beleza e do aconchego que os alunos e os educadores vivenciam no ambiente da escola.

\section{O Ensino de Arte e o Potencial Criativo do Aluno}

Duarte Junior (2007) diz que a arte objetiva expressar a visão humana em uma criação, ou seja, busca externalizar a percepção de mundo do indivíduo, suas ideias e emoções.

A arte-educação pretende utilizar a arte no processo de formação humana para dar sentido ao sentir e a percepção de mundo do ser, utilizando-se das emoções e referências simbólicas (cultura, memória, criatividade) do indivíduo. Com isto pretende educar respeitando a cultura herdada e acrescentando conhecimento a fim de dar instrumentos ao aluno para que ele venha desenvolver uma capacidade intelectual para saber 
ser crítico dentro desta mesma cultura (RODRIGUES et al., 2017).

É necessário que a escola incentive o desenvolvimento criativo da criança, pois os indivíduos têm a tendência natural de exprimir para si o que pensa e sente, e às vezes só é possível se a escola incentivar e permitir o processo de criatividade, possibilitando assim a socialização de ações e necessidades que atendam a realidade do indivíduo.

A criança tem oportunidade de se manifestar segundo seu mundo interior, assim obtém segurança no relacionamento social. As crianças possuem uma potencialidade para práticas lúdicas nas quais agem "Fazendo de conta" que são outro ser ou coisa. As práticas dramáticas devem ser levadas em consideração pelo educador, são atuações que as crianças participam com prazer.

Entende-se que dramatizar é um ato de poder que está expresso em cada indivíduo e necessita a compreensão e a representação da realidade. Segundo os PCN's (2001, p.83).

\begin{abstract}
A administração acompanha o desenvolvimento da criança como uma manifestação espontânea, assumindo feições e funções diversas, sem perder jamais o caráter de interação e de promoção de equilíbrio entre ela e o meio ambiente. Essa atividade evolui do jogo espontâneo para o jogo de regras, do indivíduo para o coletivo.
\end{abstract}

Os conteúdos de arte devem ser ensinados de forma clara e o aluno deve participar e estudar em sala de aula. O professor escolhe o modo e o recurso didático mais conveniente ao conhecimento e a aprendizagem do aluno. Para a criança a arte não é a mesma coisa que para o adulto. Para a criança é um meio de expressão, comunicação do pensamento. Toda criança desenha, e para ela coloca em jogo as interrelação do ver, do pensar, do fazer e da unidade aos domínios perceptivo, cognitivo, afetiva e motor.
[...] tanto as pessoas, individualmente, como coletivamente os sujeitos, as organizações, ou escolas, as comunidades e os grupos humanos já se complementam como exponencial de capacidades. [...] A essência do criativo exige três condições: a) potencial ou capacidade, b) geração de algo novo e diferente, pertinente com os valores, c) e comunicação ou expressão de uma ideia, realização ou proposta. (TORRE, 2009b, p. 57).

Desvendar o potencial criativo e explorá-lo é uma experiência de grande importância, que contribui não apenas para atividades profissionais, mas também para a própria existência. No entanto, o estímulo ao potencial criativo constitui em uma tarefa que parece extremamente penosa para alguns professores, talvez porque os mesmos desconhecem as possiblidades de explorar as áreas do conhecimento da criança, de despertar o interesse para a criatividade.

Segundo Suanno (2014), o potencial criativo é um processo que possibilita o aluno trabalhar o pensamento e o sentimento, em busca do conhecimento, autonomia e encontrar caminhos de interações com os outros, com a sociedade e com o meio, a partir das emoções e do experimentar e refletir a respeito das formas de decifrar a realidade.

Senso assim, cabe aos professores criar projetos que incentivem a criatividade da criança na escola, que perceba a amplitude das dimensões sociais e práticas que se associam aos conteúdos e este à realidade, oferecendo formação integral e contextualizada.

Para Suanno, (2014, p.77), "a escola tem a função, de formar indivíduos que se adeque às mais diferentes demandas, nos mais variados lugares, funções e tarefas, um indivíduo capaz de afrontar o seu próprio destino". Atualmente o desafio das escolas é o desenvolvimento dos cidadãos autônomos, prudentes, instruídos e que sejam críticos a realidade, procurando alternativas criativas e soluções que sejam inovadoras.

Neste sentido, entre arte e ensinoaprendizagem pode-se oferecer uma situação que o aluno seja capaz de conhecer e pensar sobre o 
desenvolvimento na arte e do valor e continuidade permanente dessas atitudes ao longo de sua vida. Desta forma, a arte está organizada para atender das aprendizagens do domínio do conhecimento artístico e estético ao processo pessoal de criação dos alunos, como também para sua experiência estética e conhecimento do significado que ela desempenha nas culturas humanas (PCNs, 1998).

Mesmo sendo de grande importância ao desenvolvimento da criatividade no contexto educacional, alguns elementos podem dificultar e inibir a expressão de criar, como a tendência para reproduzir e memorizar o conhecimento, dando pouca ênfase a fantasia e imaginação do indivíduo.

Toda criança tem potencial criativo, mas nem todas conseguem atingir esse potencial por não terem oportunidade de desenvolvê-lo na escola ou até mesmo no seu ambiente familiar. A criatividade precisa ser exercitada com persistência pelos professores, a partir da utilização de técnicas e estratégias voltadas para esta finalidade.

\begin{abstract}
(...) aprender criativamente possibilita ao aluno, na interação com a escola e seu planejamento, uma melhor aproximação dos conteúdos que fujam da memorização e da repetição, possibilitando, uma relação crítica e contextualizada do conhecimento, o que permite buscar e reinventar a cada dia a sua autonomia e descobrir novos caminhos de interações com os outros, com a sociedade e com o meio (SUANNO, 2014; pag. 77).
\end{abstract}

Desenvolver o potencial criativo é ver o que ninguém vê, fazendo- se valer da utilização de estratégias do saber ver e fazer que pensamento do aluno se torne visível, fazer com que pense naquilo que mais ninguém esteja pensando, estimular a fluição de ideias, auxiliando a criança a descobrir novas formas de buscar e despertar o modo criativo que há dentro de si. Necessário desenvolver a percepção da criança para que a mesma perceba que possui potencial criativo e que pode diariamente fortalece-lo cada vez mais.

\section{CONCLUSÃO}

O estudo mostrou que a arte e de primordial importância para a formação e a evolução do ser humano, e que a escola pode contribuir de forma significativa neste processo. Por meio de práticas criativas o professor pode contribuir e fazer grande diferença na vida da criança fazendo-a ver um mundo além do que se é ensinado no dia-a-dia, na sala de aula, ofertar algo que possa ultrapassar o mundo da imaginação e melhor desenvolver o senso criativo da criança a partir da capacidade do professor de procurar ampliar a arte e a criatividade no ambiente escolar.

O ensino da arte transforma a concepção que a criança tem sobre si, e a leva a desenvolver a capacidade de expressão, a linguagem verbal e não verbal e por meio da criatividade transcende o imaginário e a percepção de realidade.

Compreende-se que é necessário estimular o potencial criativo que cada criança possui, para que ela possa ter autoconfiança e autonomia para desenvolver a sua criatividade para experimentar as diversas formas do que está em sua volta de modo que possa compreender e se sensibilizar com o ambiente e com o próximo.

A criatividade é a ação formadora e transformadora, que interliga o conhecimento e potencializa o ser humano como um todo e se caracteriza pelas suas vivências que promove, pelo despertar da curiosidade pelo mundo e pelas chances que são dadas para criar. No ensino de arte, o educador deve proporcionar a criança no ensino fundamental todas as oportunidades e estímulos de criação e protagonismo de forma contextualizada e integrada.

\section{AGRADECIMENTO}

Agradeço primeiramente ao meu Deus pelo o milagre de ter sido uma das contempladas para estar publicando o artigo nesta revista. Meus 
agradecimentos a minha querida professora e orientadora Edna Maria da Cruz Pinho, a minha filha Erika Flaviane P de Souza Braga, psicóloga, que foi minha maior incentivadora para estar participando da SICTEG e a publicar o artigo e aos demais que fizeram parte deste processo direta ou indiretamente

Todos os autores declararam não haver qualquer potencial conflito de interesses referente a este artigo.

\section{REFERÊNCIAS}

ALMEIDA, C. Concepções e práticas artísticas na escola. In $\mathrm{O}$ ensino das artes: Construindo caminhos. Sueli Ferreira (Org.). Campinas: Papirus, 2001.

ASSIS, L. C. Práticas e atributos pessoais docentes que favorecem o desenvolvimento da criatividade dos alunos na educação infantil, 2009.

BESSA, M. Artes plásticas entre as crianças. 3 ed. Rio de Janeiro: José Olimpio, 1972.

BRASIL, Ministério da Educação. Lei de Diretrizes e Bases da Educação Nacional. Lei no 9.394/96, de 20 de dezembro de 1996. Estabelece as diretrizes e bases Educação Nacional. Brasília: MEC/SEF, 1998.

BRASIL, Base Nacional Comum Curricular. Educação é a Base. Disponível em: < http://basenacionalcomum.mec.gov.br/a-base>. Acessado em 27 mai de 2019.

BRASIL, Parâmetros Curriculares Nacionais Arte. Brasília, 1997. Disponível em: <http://portal.mec.gov.br/seb/arquivos/pdf/livro06.pd f $>$. Acesso no dia 20 de março de 2019.

BRASIL, Parâmetros Curriculares Nacionais Arte. Brasília, 1998. Disponível em: $<$ portal.mec.gov.br/seb/arquivos/pdf/arte.pdf>. Acessado em: 09 de abr de 2019.

BRASIL ,Lei $\mathbf{n}^{0} \mathbf{1 3 . 4 1 5}$, de 16 de fevereiro de 2017. Altera a Lei no 9.394, de 20 de dezembro de 1996, que estabelece as diretrizes e bases da educação nacional, no tocante ao ensino da arte. Disponível em: $<$ http://www.planalto.gov.br/ccivil_03/_ato20152018/2017/lei/113415.htm>. Acesso em: 04 mai 2019.

DUARTE JUNIOR, J. F. Por que arteeducação?.6.ed. Campinas,Sp:Papirus,2007.

FARIAS, G. I. Afetividade na sala de aula: o olhar Walloniano sobre a relação professor-aluno na educação infantil. Aparecida de Goiania. Aparecida de Goiânia: Instituto Superior de Educação da Faculdade Alfredo Nasser, 2010.

GARCIA, J. F. D. e LOPES, L. F. A Importância Da Arte Nos Anos Iniciais. Disponível em: < uniesp.edu.br/sites/_biblioteca/revistas/20170602124 521.pdf> Acessado em: 20 de mar de 2019.

LINS, M. J. S. C; MIYATA, E. S. Avaliando a aprendizagem de criatividade em uma oficina pedagógica. Ensaio: aval.pol.públ.Educ., Rio de Janeiro , v. 16, n. 60, p. 455-468, Sept. 2008. Disponivel em: <Available from $<$ http://www.scielo.br/scielo.php?script=sci_arttext\& pid $=$ S0104-0362008000300008\&lng=en\&nrm=iso $>$. access on 06 Mar. 2019.

LIMAVERDE. P. Pedagogia ecossistêmica. educação transdisciplinar da Escola Vila. Fortaleza. Editora da Vila, 2015.

MEC. Base nacional Comum Curricular. 1997. Disponível em: http://basenacionalcomum.mec.gov.br/a-base. Acesso no dia 25 de março de 2019.

MOSER, V. M. D. N. de. A criatividade: a necessidade da promoção da atividade criadora o pré-escolar. 2015. Tese de Doutorado.

NASCIMENTO, P. L. Parâmetros para análisesíntese de práticas educativas. In: SUANNO, M. V. R. et al. (Orgs.) Resiliência, criatividade e inovação: potencialidades transdisciplinares na educação. Goiânia: UEG/Ed. América, 2013. p. 75-99.

OLIVEIRA, E. B. P.; DE ALENCAR, E. M. L. S. Importância da criatividade na escola e no trabalho docente segundo coordenadores pedagógicos. Estudos de Psicologia, v. 29, n. 4, p. 541-552, 2012.

PINHO, M.J de; et al. Projetos criativos na prática pedagógica: cantar e encantar a aprendizagem. A escola de mãos dadas com as diferenças: uma experiência de criatividade e colaboração no sul do Tocantins. p. 55-77. Maria José de Pinho, Marilza Vanessa Rosa Suanno, João Henrique Suanno (orgs.). Goiânia:/Editora Espaço Acadêmico, 2015.

RODRIGUES, R. N. L.; SOUZA, L. J. de; TREVISO, V. C. ARTE-EDUCAÇÃO: A RELEVÂNCIA DA ARTE NO PROCESSO. Cadernos de Educação: Ensino e Sociedade, Bebedouro SP, 4 (1): 114-126, 2017.

SEVERINO, A. J. Metodologia do trabalho Cientifico. - 23 ed. rev. E atual. - São Paulo: Cortez, 2007. 
SOUZA, N. M.; WECHSLER, A. M.. Reflexões sobre a teoria piagetiana: o estágio operatório concreto. Cad Educ Ens Soc, v. 1, n. 1, p. 134-50, 2014.

SUANNO, J. H. A escola que desenvolve seu potencial criativo IN SCHROEDER, Edson; SILVA, Vera Lúcia de Souza e. Novos Talentos: processos educativos e ecoformação, Blumenau, SC, editora Legere, 2014. p.77-84.

TORRANCE, E. P. Torrance tests of creative thinking: verbal tests, forms a and $B$, figurals tests, forms a and B: norms-technical manual. Personel Press/Ginn, Xerox Education Company, 1974.

TORRE, S. de la. Uma escola para o século XXI: escolas criativas e resiliência na educação. Florianópolis: Insular, 2009. 